\title{
Pleiotropic Protective Effects of Phytochemicals in Alzheimer's Disease
}

\author{
Sergio Davinelli, ${ }^{1}$ Nadia Sapere, ${ }^{1}$ Davide Zella, ${ }^{2}$ Renata Bracale, ${ }^{1}$ \\ Mariano Intrieri, ${ }^{1}$ and Giovanni Scapagnini ${ }^{1}$ \\ ${ }^{1}$ Clinical Biochemistry and Clinical Molecular Biology Laboratory, Department of Health Sciences, University of Molise, \\ 86100 Campobasso, Italy \\ ${ }^{2}$ Department of Biochemistry and Molecular Biology, Institute of Human Virology, University of Maryland-School of Medicine, \\ Baltimore MD 21201, USA \\ Correspondence should be addressed to Giovanni Scapagnini, g.scapagnini@gmail.com
}

Received 10 February 2012; Accepted 27 March 2012

Academic Editor: Cristina Angeloni

Copyright ( $) 2012$ Sergio Davinelli et al. This is an open access article distributed under the Creative Commons Attribution License, which permits unrestricted use, distribution, and reproduction in any medium, provided the original work is properly cited.

\begin{abstract}
Alzheimer's disease $(\mathrm{AD})$ is a severe chronic neurodegenerative disorder of the brain characterised by progressive impairment in memory and cognition. In the past years an intense research has aimed at dissecting the molecular events of AD. However, there is not an exhaustive knowledge about $\mathrm{AD}$ pathogenesis and a limited number of therapeutic options are available to treat this neurodegenerative disease. Consequently, considering the heterogeneity of $\mathrm{AD}$, therapeutic agents acting on multiple levels of the pathology are needed. Recent findings suggest that phytochemicals compounds with neuroprotective features may be an important resources in the discovery of drug candidates against AD. In this paper we will describe some polyphenols and we will discuss their potential role as neuroprotective agents. Specifically, curcumin, catechins, and resveratrol beyond their antioxidant activity are also involved in antiamyloidogenic and anti-inflammatory mechanisms. We will focus on specific molecular targets of these selected phytochemical compounds highlighting the correlations between their neuroprotective functions and their potential therapeutic value in $\mathrm{AD}$.
\end{abstract}

\section{Introduction}

Alzheimer's disease $(\mathrm{AD})$ is a decisive challenge to the health care system throughout the world and it is the result of a long chain of events leading to neuronal dysfunction and impairment in memory and cognitive abilities. The two core pathological hallmarks of $\mathrm{AD}$ are senile plaques (SPs) and neurofibrillary tangles (NFTs). To date, there are several experimental reports supporting the idea that oxidative stress is associated with the early development of $\mathrm{AD}$ [1]. In addition, recent studies suggest that inflammatory processes may significantly contribute to the progression of $\mathrm{AD}$ [2]. Specifically, the aggregation of beta-amyloid $(\mathrm{A} \beta)$ oligomers activate different signaling pathways through interactions with neuronal membranes causing oxidative stress and inflammatory responses. Furthermore, $\mathrm{A} \beta$ plaques can interfere with the neurotransmitter acetylcholine (ACh) affecting synaptic transmission and initiate inflammatory mechanisms that produce reactive oxygen species (ROS) [3]. Another cause that leads to cell death in $\mathrm{AD}$ is the hyperphosphorylation of tau protein that normally stabilizes the microtubules. When tau presents a high level of phosphorylation it becomes dysfunctional; therefore the microtubule collapse and the resulting NFTs block neurotransmitters and neuronal signaling. However, AD is a multifaceted neurodegenerative disorder and the researchers do not know enough about the biology of $\mathrm{AD}$ to identify the right targets. Since we do not have a comprehensive picture of the disease, the therapeutic landscape for $\mathrm{AD}$ is wide open. Moreover, it is necessary to emphasize that the new therapies must be based on molecular target and biomarkers. For instance, a good biomarker would be useful in the clinic but it could also help to design drugs to slow the decline [4]. Currently, a successful treatment is lacking and the medications available do not delay or modify 
<smiles>COc1cc(/C=C/C(=O)/C=C/c2ccc(O)c(OC)c2)ccc1O</smiles>

Enol form<smiles>COc1cc(/C=C/C(=O)CC(=O)/C=C/c2ccc(O)c(OC)c2)ccc1O</smiles>

Keto form

FIgure 1: Chemical structures of Curcumin. Curcumin belongs to the class of curcuminoids and the presence of double bonds increases its potency and reactivity. The phytochemical curcumin undergoes keto-enol tautomerism.

the disease progression even though several potential drug targets have been identified. In this scenario, plant-derived compounds with multiple target mechanisms might play a role in drug development and discovery. A number of studies demonstrated potential health-promoting properties in the use of natural products as therapeutics for $\mathrm{AD}[5,6]$. Moreover several epidemiological reports have documented the influence of dietary habits on the incidence of neurodegenerative disorders. In particular, it was suggested a significant positive correlation between the consumption of polyphenolic phytochemical-rich foods and the prevention of certain neurological diseases, including $\mathrm{AD}$ [5]. Although these findings need to be interpreted with caution and it is still early to define such compounds as neuroprotective, several observations raise the possibility that they might have protective effects and might be able to slow the progression of $\mathrm{AD}$. Among the numerous natural products of emerging interest with anti-AD properties, we will focus on some polyphenolic phytochemicals and on their potential role as antiamyloidogenic, anti-oxidative, and anti-inflammatory activities, highlighting specific molecular targets that might play a crucial function in the neuroprotection from AD.

\section{Some Candidates Polyphenolic Phytochemicals for the Neuroprotection from $\mathrm{AD}$}

Polyphenols are a class of plant-derived substances characterized by the presence of more than one phenol structural unit. In the plants, they are involved in the defence from pathogens attacks or stress induced by chemical and physical damage. These compounds exert their protective action also in the animals by modulating several intracellular processes that preserve the neurons. In the following sections, we include some polyphenolic compounds, such as curcumin, (-)epigallocatechin-3-gallate (EGCG) and resveratrol, that have received attention as alternative candidates for $\mathrm{AD}$ therapy.

2.1. Curcumin. Curcumin (1,7-bis [4-hydroxy-3-methoxyphenyl]-1,6-heptadiene-3,5-dione) or diferuloylmethane is extracted from the rhizome of Curcuma longa [7]. The structure is often shown in the keto form, but recent NMR studies demonstrated that curcumin exists in solution as ketoenol tautomers [8] (Figure 1). Numerous pieces of evidence suggest that curcumin may be a promising therapy for $\mathrm{AD}$ because it has different neuroprotective activities, including antioxidant [9], anti-inflammatory [10] and antiamyloidogenic properties [11]. Curcumin has been demonstrated to have a strong antioxidant neuroprotective effects, scavenging ROS [12] and neutralizing nitric-oxide-(NO-) based free radicals [13]. However, one of the issues of curcumin as a therapeutic agent in the treatment of $\mathrm{AD}$ is its poor water solubility [14], which is one reason for its low bioavailability following oral administration or through parenteral route [15]. The poor bioavailability is one of the causes of its failure in randomized control trials for AD. The structural features of curcumin that can contribute to the antioxidant activity are the phenolic and the methoxy group on the phenyl ring and the 1,3-diketone system. Moreover, the antioxidant activity of curcumin increases when the phenolic group with a methoxy group is at the ortho position $[16,17]$. The orthomethoxy group can form an intramolecular hydrogen bond with the phenolic hydrogen, making the $\mathrm{H}$-atom abstraction from the orthomethoxyphenols surprisingly easy [18]. The $\mathrm{H}$ abstraction from these groups is responsible for the remarkable antioxidant activity of curcumin. Moreover, the reactions of curcumin with free radicals produce a phenoxyl radicals and a carbon-centered radical at the methylene $\mathrm{CH}_{2}$ group [19] (Figure 2). Additional experimental reports supporting the antioxidant property of curcumin were provided by Lim and coworkers using an $\mathrm{AD}$ transgenic mouse model which demonstrated that curcumin reduces brain levels of oxidized proteins containing carbonyl groups [20]. In vivo, the antioxidant activity of curcumin may be mediated through antioxidant enzymes such as superoxide dismutase (SOD), catalase (CAT), and glutathione peroxidase (GSH-Px). Curcumin has been shown to serve as a Michael acceptor, reacting with glutathione (GSH) and thioredoxin [21]. Depletion in cellular GSH levels is an important measure of oxidative stress, which is implicated in the pathogenesis of $\mathrm{AD}$. A study on postmortem brain of $\mathrm{AD}$ patients has revealed decreased levels of GSH in some area of the brain [22]. Also, the GSH levels were low in the red blood cells of male $\mathrm{AD}$ subjects, confirming an association between GSH and AD [23]. Noteworthy, there are some studies reporting the restorative effect of curcumin on 


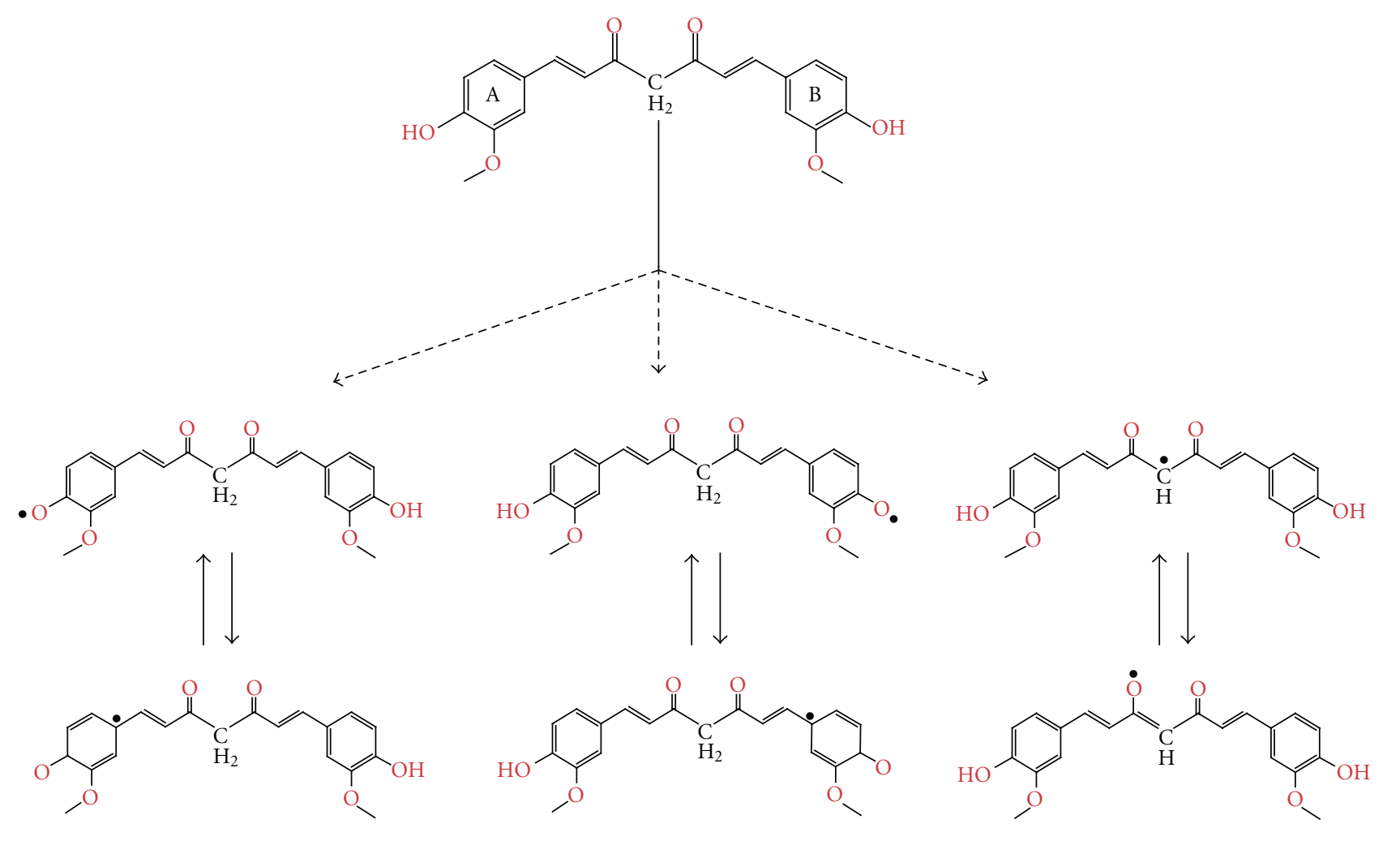

FIGURE 2: Reaction mechanism of curcumin with free radicals. The reactions produce phenoxyl radicals and carbon-centered radical at the methylene $\mathrm{CH}_{2}$ group.

GSH depletion. For instance, it was demonstrated that curcumin is able to replenish the intracellular GSH pool by changing the nuclear content and/or activation of specific transcription factors such as 12-tetradecanoate 13acetate (TPA-) responsive elements (TRE) and electrophilic response element (EpRE) [24]. Moreover, curcumin enhances the antioxidant enzyme activities of SOD and CAT in the striatum and mid-brain of 1-methyl-4-phenyl-1,2,3,6tetrahydropyridine- (MPTP-) injected mice [25]. Taking into account that in vivo evidence showed that peroxynitrite induces Alzheimer-like tau hyperphosphorylation, nitration, and accumulation [26], it was reported that curcumin mediates the direct detoxification of reactive nitrogen species such as peroxynitrite, thus exerting an antioxidant activity [27]. Furthermore, the pieces of evidence to support a role of oxidative stress in $\mathrm{AD}$ brain with elevated levels of lipid peroxidation increasing [28]. Oxidative damage of lipids generates toxic aldehydes such as 4-hydroxy-2-nonenal (4HNE) and malondialdehyde (MDA) leading to cell death. Important cytopathologies in $\mathrm{AD}$ brain include a decreased activity of all electron transport chain complexes [29]. In particular, complex IV decreases in $\mathrm{AD}$, which causes release of oxidants during mitochondrial electron transport [30]. It was reported that excessive $\mathrm{A} \beta$ binds to regulatory heme, triggering functional heme deficiency and causing the key cytopathologies of $\mathrm{AD}$. Additionally, $\mathrm{A} \beta$-heme complex is a peroxidase and curcumin significantly inhibits the peroxidase activity of $\mathrm{A} \beta$-heme [31]. The Tg2576 mouse model of $\mathrm{AD}$ exhibits impaired mitochondria metabolic activity in the spinal cord and curcumin partially suppressed the mitochondrial impairment reversing motor function deficits [32]. Interestingly, curcumin treatment abrogates lipid peroxidation protecting mitochondria from oxidative damage and apoptosis in cortical neurons [33]. Moreover, curcumin has been also shown in PC12 cells to provide protection against the deleterious effects of 4-HNE on mitochondrial redox metabolism, cytochrome $\mathrm{c}$ release, and DNA fragmentation [34]. The increased level of oxidative stress in $\mathrm{AD}$ is reflected by the increased brain content of iron $\left(\mathrm{Fe}^{2+}\right)$ and copper $\left(\mathrm{Cu}^{2+}\right)$ both capable of stimulating free radical formation. In addition to its properties of quencher, curcumin showed to be able to bind $\mathrm{Cu}^{2+}$ and $\mathrm{Fe}^{2+}$ ions [35]. Since these redox-active metals ions can intensify $\mathrm{A} \beta$ aggregation, curcumin may prevent this aspect of $\mathrm{AD}$ pathogenesis. Other reports suggested that curcumin regulates $\mathrm{Fe}^{2+}$ metabolism by modulation of $\mathrm{Fe}^{2+}$ regulatory proteins; therefore it may act as an iron chelator [36]. Significantly, in vivo studies reported that another divalent metal cation such as zinc $\left(\mathrm{Zn}^{2+}\right)$ is highly enriched in $\mathrm{A} \beta$ plaques $[37,38]$ but its role in the amyloid landscape is still poorly understood and under investigation. However, even though curcumin more readily binds to the redoxactive metals such as $\mathrm{Cu}^{2+}$ and $\mathrm{Fe}^{2+}$, it was also reported relatively weak affinity for the redox-inactive metal $\mathrm{Zn}^{2+}$ which might exert a small protective effect against $A \beta$ by inducing metal chelation [35]. Recently, a systematic review 
highlighted the importance of inflammatory processes in the pathogenesis of $\mathrm{AD}$ [39]. AD secretes increasing levels of multiple inflammatory mediators, and considering the antiinflammatory characteristic of curcumin, it was reported that this polyphenol reduced the level of interleukin- $1 \beta$ (IL-1 $\beta$ ), a proinflammatory cytokine that appears elevated in the brains of AD-like mice [20]. Findings on the antiinflammatory effects of curcumin were also provided by Jin et al. demonstrating that this natural phenol reduces the release of proinflammatory cytokines, such as IL-1 $\beta$, IL-6, and tumor necrosis factor-alpha (TNF- $\alpha$ ) [40]. Indeed, curcumin abolished the proliferative effects of IL- 6 because it inhibits the phosphorylation of signal transducer and activator of transcription 3 (STAT3) [41]. In a similar manner, curcumin downregulates the transcription factor activator protein 1 (AP1) through direct interaction with its DNA binding motif [42] and inducing the inhibition of IL- $1 \alpha$ and TNF- $\alpha$ [43]. Several experimental lines suggest that the anti-inflammatory capacity of curcumin is associated to the reduction of the activity of nuclear transcription factors NF$\mathrm{k} \beta$ signaling pathway [44]. NF- $\mathrm{k} \beta$ enhances the transcription of proinflammatory genes, such as inducible nitric oxide synthase (iNOS). In inflammatory cells, iNOS catalyzes the synthesis of NO, which can react with superoxide to form peroxynitrite which damages proteins and DNA. Curcumin has been found to inhibit NF- $k \beta$-dependent gene transcription and the induction of iNOS in animal studies and macrophages cell culture $[45,46]$. Probably, the inhibition of AP1 and NF-k $\beta$ occurs through the chromatin remodelling activity of curcumin that is able to modulate some histone deacetylases (HDAC) activity [47]. Moreover, curcumin attenuates the inflammatory responses through the inhibition of lipoxygenase and cyclooxygenase2 (COX-2) enzymes, which are responsible of the synthesis of proinflammatory prostaglandins and leukotrienes [48]. Interestingly, the anti-inflammatory and neuroprotective effects of curcumin against dopamine induced neuronal death have also been demonstrated by Lee and coworkers which established that the inflammatory conditions induced by microglial activation are the main target for curcumin [49]. Noteworthy, curcumin exhibits protective effects on neuronal cells by inhibiting the aggregation of $A \beta$ into oligomers and clearance effect on the exsting $\mathrm{A} \beta$ [50]. A very interesting in vivo approach with multiphoton microscopy showed the ability of curcumin to cross the blood-brain barrier (BBB) and disrupt amyloid plaques [51]. Additionally, in aged female rats with induced AD-like phenotype, curcumin prevented $\mathrm{A} \beta$-induced spatial memory deficits in the Morris water maze assay, postsynaptic density loss, and reduced $A \beta$ deposits [52]. As mentioned above, curcumin is able to clear amyloid plaques through several mechanisms and an additional activity that may be relevant is the induction of heat shock proteins (HSPs) molecular chaperones that are able to block protein aggregate formation [53]. However, even though several experimental research showed that curcumin exhibit high affinity binding to $A \beta$ aggregates, one study reported the relationship between the tautomeric structures of curcumin, its derivatives, and their $A \beta$-binding activities. In particular, the results achieved by UV-visible spectroscopy

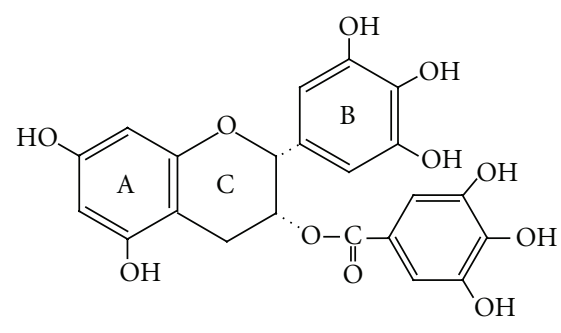

EGCG

Figure 3: Chemical structure of (-)-Epigallocatechin-3-gallate. EGCG contains three heterocyclic rings, A, B, and C, and the free radical scavenging property of EGCG is attributed to the presence of trihydroxyl group on the $\mathrm{B}$ ring and the gallate moiety at the $3^{\prime}$ position in the $\mathrm{C}$ ring.

revealed that the enolization is crucial for the binding and the enol forms of the curcumin derivatives are the predominant binding species for $A \beta$ aggregates [54]. These important findings may represent a novel strategy for the design of therapeutic drugs or diagnostic tools in AD. Recently, Longvida, a curcumin formulation, has been evaluated in a Phase II Alzheimer's clinical trial (NCT01001637). Taking into account the low bioavailability of curcumin and its inability to reach required blood concentrations necessary to affect disease markers, Longvida is a solid lipid curcumin particle (SLCP) preparation and it was reported relatively higher bioavailability of SLCP compared to generic curcumin extract. Furthermore, this formulation is able to maintain plasma concentration of curcumin above the threshold required for the biological activity [55].

\section{2. (-)-Epigallocatechin-3-gallate (EGCG). EGCG} $([(2 R, 3 R)-5,7-d i h y d r o x y-2-(3,4,5$-trihydroxyphenyl) chroman-3-yl] 3,4,5-trihydroxybenzoate) (Figure 3) is the most common phenolic constituent of green tea with several pharmacological activities associated with different beneficial health effects. It was well documented a powerful free radical scavenging activity for this catechin which might be attributed to the presence of the trihydroxyl group on the $\mathrm{B}$ ring and the gallate moiety esterified at the $3^{\prime}$ position in the $\mathrm{C}$ ring [56]. Furthermore, it was demonstrated in a human model of BBB the pharmacokinetics of catechin and epicatechin that could cross the BBB in a time-dependent manner [57]. EGCG penetrates the BBB at a low rate and the bioavailability after oral administration was approximately 5\% [58]. It should be noted that high doses of EGCG were associated to death in rat hippocampal neuron through the mitochondrial-dependent pathway [59] and also that at high concentrations it has a prooxidant/proapoptotic activity [60]. However, considering that $\mathrm{A} \beta$ can induce mitochondrial dysfunction, it was also demonstrated that EGCG treatment is able to restore mitochondrial respiratory rates, altered mitochondrial membrane potential, and ROS production or ATP levels [61]. An increasing number of publications reports the ability of EGCG to modulate multiple biological pathways. Indeed, it has been shown to 
regulate several biomedically important targets and to exert neuroprotection in many ways. In addition to the antiinflammatory properties, EGCG exerts protection by regulating different survival genes and controlling numerous antioxidant protective enzymes [62]. Advanced glycation end-products are involved in the neuronal injury associated with several neurodegenerative disorders. EGCG increased SOD activity and protected against glycation end productsinduced neurotoxicity by decreasing ROS and MDA [63]. Another demonstration that EGCG may have preventive and/or therapeutic potential in $\mathrm{AD}$ has been shown in BV2 microglia cell lines and in rat hippocampus where EGCG treatment increased cellular GSH pool through elevated mRNA expression of gamma-glutamylcysteine ligase (GCL) which provides neuroprotection from $\mathrm{A} \beta$ cytotoxicity [64]. On D-galactose-treated aged mice, EGCG treatment led to the increment of SOD and GSH-Px activities decreasing MDA contents in the hippocampus [65]. Moreover, it is interesting that the attenuation of monoamine oxidase (MAO) activity may provide protection against oxidative neurodegeneration. EGCG supplementation in adult rat brains was able to exert an inhibitory action on MAO-B preventing physiological peroxidation [66]. As mentioned above for the curcumin, EGCG acts as an antioxidant protecting rat hippocampal neurons against NO stressinduced neuronal damage by deoxidizing peroxynitrate/ peroxynitrite produced after ischemia [67]. Recently, it was established the pivotal role of iron in neurodegeneration and recent studies examined the effect of EGCG in the $\mathrm{Fe}^{2+}$ chelating process demonstrating neurorestorative activity and $\mathrm{Fe}^{2+}$-chelating properties [62]. Considering that the binding of EGCG to $\mathrm{Fe}^{2+}$ is essential for its antioxidant activity, among 12 phenolic compounds tested EGCG is the most potent inhibitor of the $\mathrm{Fe}^{2+}$-mediated DNA break [68]. A considerable number of evidence have elucidated the importance of several cell signaling pathways in the neuroprotective action of EGCG. Several studies indicate that EGCG affects mitogen-activated protein kinases (MAPK), $\mathrm{NF}-\mathrm{k} \beta$ and protein kinase C (PKC) pathways [69]. In support of these observations, EGCG has been shown to mediate the phosphorylation of $\mathrm{PKC}$ promoting the survival of human neuroblastoma SH-SY5Y cells from $A \beta$ and 6-hydroxydopamine (6-OHDA)-induced neurotoxicity [70]. Other evidence on the pharmacological actions of EGCG and its potential therapeutic applications to various neurodegenerative diseases such as AD were provided by Kim et al. EGCG in human astrocytoma U373MG cells suppressed NF- $\mathrm{k} \beta$ activation and phosphorylation of MAPK p38 and the c-Jun N-terminal kinase [71]. Additional investigations have indicated that EGCG prevented the expression of COX-2, iNOS, the release of NO, and proinflammatory cytokines from astrocytes and microglia by inhibiting MAPK signaling cascades [72]. Moreover, administration of EGCG prevented lipopolysaccharide(LPS-) mediated apoptotic cell death through the reduction of the levels of $\mathrm{A} \beta$ and inhibited the elevation of the expression of iNOS and COX-2 [73]. Considerably, EGCG is able to modulate enzymes that are involved in amyloid precursor protein (APP) processing and reduces the

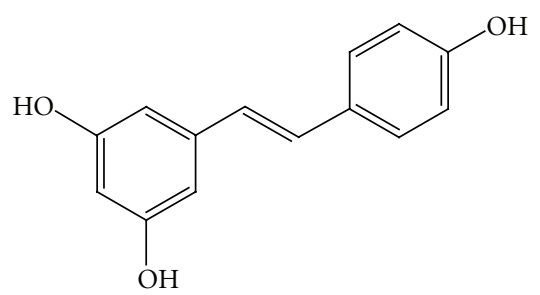

Resveratrol

FIgURE 4: Chemical structure of resveratrol. The $4^{\prime}-\mathrm{OH}$ in resveratrol provides its chemical and biological features. The transfer of protons or hydrogen atoms to reactive species appears to be crucial to its antioxidant mechanism.

formation of $\beta$-amyloid plaques in cell culture and in vivo [74]. Intraperitoneal administration of EGCG attenuated brain $A \beta$ neuropathology and improved cognitive function in a transgenic $\mathrm{AD}$ mouse model [75]. In particular, EGCG inhibits the fibrillogenesis of $A \beta$ through the binding to the natively unfolded polypeptides and preventing their conversion into toxic aggregates intermediates [76]. Considering the inhibitory function of EGCG on the $A \beta$ generation, it was previously shown that catechins are able to inhibit formation, extension, and destabilization of $\beta$-amyloid fibrils [77] and EGCG mediates the block of $\beta$-secretase activity [78]. Additionally, Obregon and coworkers studied the involvement of three candidate $\alpha$-secretase enzymes in EGCG-induced nonamyloidogenic APP metabolism. The results showed that a-disintegrin and metalloprotease-10 (ADAM-10) is necessary for EGCGmediated $\alpha$-secretase cleavage activity in APP processing; thus potential stimulators of ADAM-10 such as EGCG could prevent the amyloidosis associated to $\mathrm{AD}$ [79]. A further study revealed that through the inhibition of extracellular signal-regulated protein kinase (ERK) and NF- $\mathrm{k} \beta$ pathways, the treatment with EGCG in mutant $\mathrm{AD}$ mice improved memory function enhancing the $\alpha$-secretase function and reducing the activities of $\beta$-and $\gamma$-secretases with subsequently decrease in the levels of $A \beta$ [80]. It has also been reported synergistic effects between EGCG and fish oil on the decrease in AD-like pathology in $\operatorname{Tg} 2576$ mice [81] and in a recent study Li et al. showed that the administration of this or similar compound may improve spatial memory preventing the decrease in the proteins involved in the synaptic function and structure [82]. EGCG has a wide array of biological effects and it is a promising compound which has been proven efficacious in AD animal models. Lastly, EGCG has an excellent tolerability and has resulted in ongoing Phase II/III clinical trials (NCT00951834).

2.3. Resveratrol. Resveratrol (5-[(E)-2-(4-hydroxyphenyl) ethenyl] benzene-1,3-diol) is a phytoalexin polyphenolic compound (Figure 4) found in grapes and other plants. In recent years many studies have reported interesting insights about the antiaging effects of resveratrol in different organisms including nematodes, yeast, rat, and mice. Indeed, resveratrol modulates various systems that protect cells 
providing neuroprotective features both in vitro and in vivo in models of AD. Many studies reported that the central nervous system (CNS) is one of the resveratrol's targets. This compund is able to pass the BBB [83] but the bioavailability is low because it is quickly metabolized into glucuronide and sulfate conjugates. Several lines of evidence indicate a strong antioxidant functions together with other pharmacological activities, therapeutic and protective properties [84]. Regarding the radical-scavenging activity, structural studies and theoretical calculations demonstrate that in the antioxidant reaction of resveratrol the hydroxyl group at the $4^{\prime}$-position is much easier to subject to oxidation than other hydroxyl groups [85]. Intraperitoneally administration of resveratrol exerts neuroprotective properties upregulating several endogenous antioxidant enzymes such as SOD and CAT [86]. Prolonged administration of resveratrol improves colchicine-induced cognitive impairment, reduces MDA and nitrite levels, and restores depleted GSH [87]. However, it is important to emphasize that resveratrol can exhibit prooxidant activities in the presence of transition metal ions such as $\mathrm{Cu}^{2+}$, leading to oxidative breakage of cellular DNA [88]. A substantial amount of research has attributed to this phytocompound the capacity to increase the activity of SIRT1 that are $\mathrm{NAD}^{+}$-dependent class III histone deacetylases [89]. Consequently, resveratrol appears to possess the ability to activate sirtuins and to mimic caloric restriction [84]. In a mouse model of $\mathrm{AD}$, a calorie-restricted diet attenuates $\mathrm{AD}$ pathogenesis through an increase in SIRT1 activity [90]. Additionally, it was reported that caloric restriction reduces $\mathrm{A} \beta$ deposition and $\mathrm{A} \beta$-associated neuropathology in different animal models [91, 92]. In a meaningful way Kim et al. showed in transgenic AD mouse model that resveratrol reduced neurodegeneration through a decrease in the acetylation of known SIRT1 substrates, for example, peroxisome-proliferator-activated receptor gamma coactivator alpha (PGC-1 $\alpha$ ) and p53 [93]. SIRT1 activated by resveratrol protects cells against $\mathrm{A} \beta$-induced $\mathrm{ROS}$ production and reduces amyloid neuropathology in the brains of Tg2576 mice [94]. Taking into account that resveratrol can be considered a neuroprotective compound in the context of $\mathrm{AD}$, it is possible to speculate that the ability to counteract $\mathrm{A} \beta$ toxicity can occur through its antioxidant properties but also through SIRT1 activation. Definitely, resveratrol is reported to possess antiamyloidogenic activity in several studies, for example, the treatment with this stilbenoid resulted in the inhibition of $\beta$-amyloid peptide polymerization even though the antiamyloidogenic mechanism is still unknown [95]. As illustrated by Marambaud and colleagues, resveratrol promotes clearance of intracellular $\mathrm{A} \beta$ by activating its proteasomal degradation [96]. Moreover, SIRT1 overexpression reduces $\mathrm{A} \beta$ pathology in APP-expressing neuronal cultures by delaying $A \beta$ synthesis $[96,97]$. A recent work offers interesting insights into the effects of resveratrol on the polymerization, cell toxicity, and destabilization of $\mathrm{A} \beta$ fibril suggesting that resveratrol disrupts $\mathrm{A} \beta$ hydrogen binds thus preventing fibril formation, destabilizing preformed fibril without affecting oligomerization [98]. Furthermore, in a different study it was noticed that the protective effects of resveratrol on $\beta$-amyloid protein-induced toxicity in rat hippocampal cells are related to activation of PKC [99]. It is noteworthy to mention that resveratrol might be involved in the attenuation of neuroinflammatory responses because it is able to reduce the concentration of 8-iso-prostaglandin $\mathrm{F} 2 \alpha$, an indicator of free radical generation [100]. It has also been shown that resveratrol inhibits COX-1 but in contrast it does not affect the expression of COX-2 [100]. Since NF-k $\beta$ signaling activation plays an important role in the neurodegeneration, another link between $\mathrm{AD}$ and neuroprotective activity of resveratrol is its ability to reduce the expression of genes modulated by NF-k $\beta$, such as iNOS, prostaglandin E2 (PGE2), as well as cathepsin and NO [101]. One of the main findings reported by $\mathrm{Lu}$ et al. was that resveratrol attenuates LPS-stimulated NF- $\kappa$ B activation in murine primary microglia and astrocytes and suggests that the inflammatory responses induced by LPS could be limited by resveratrol, with different potencies [102]. Studies performed in ischemia-reperfusion models have demonstrated that resveratrol inhibits peroxisome proliferatoractivated receptors alpha $(\operatorname{PPAR} \alpha)[103]$ and reduces NF$\mathrm{k} \beta$ p65 expression [104]. Moreover, resveratrol was found to activate AMPK and reduce cerebral $\mathrm{A} \beta$ levels and deposition in the mice cortex [105]. Using electron microscopy and biochemical methods, it was reported that resveratrol prevents the abnormal expression of peroxiredoxins but also mitochondrial structural abnormalities in a mouse model of primary $\mathrm{AD}$ and $\mathrm{A} \beta$-incubated mouse neuroblastoma cells [106].

Currently, resveratrol is under Phase III clinical trials (NCT00678431) studies to determine the effects in mild-to moderate $\mathrm{AD}$ in combination with glucose and malate.

\section{Activation of the Keap1/Nrf2 System for Neuroprotection by Curcumin, EGCG, and Resveratrol}

Nuclear factor erythroid 2-related factor 2 (Nrf2) is a conserved master regulator of cellular antioxidant responses. As mentioned above, multiple pieces of evidence support the role of oxidative stress in the pathogenesis of $\mathrm{AD}[1]$. Therefore, Nrf2 appears to be a good candidate to provide neuroprotection in $\mathrm{AD}$. Nrf2 belongs to the $\mathrm{CnC}$ (Cap'n'Collar) family leucine zipper transcrption factors and regulates the expression of genes encoding antioxidant and detoxifying proteins such as glutathione S-transferase (GST), glutathione synthetase (GSS), heme oxygenase 1 (HO-1) and $\mathrm{NAD}(\mathrm{P}) \mathrm{H}$ :quinone oxidoreductase [12]. Under basal conditions, Nrf2 is sequestered in the cytoplasm by Keap1 (Kelch-like ECH-associating protein 1), which facilatites its polyubiquitylation and proteasome-mediated degradation. Keap 1 functions as a sensor of stress signals and the exposure to electrophiles, oxidants, or xenobiotics disrupts Keap1Nrf2 complex, thus stabilizing Nrf2 and allowing it to accumulate in the nucleus. Nrf2 activates the trascrption of its target genes via antioxidant response elements (AREs) in their promoter regions binding as a heterodimer with the members of Maf and Jun family [12]. To date, only few pieces of evidence show that the activation of $\mathrm{Nrf} 2$ and of its cytoprotective genes by curcumin, EGCG, and resveratrol 
treatments is sufficient to protect against AD. However, Chen et al. reported that resveratrol is able to increase the expression of HO-1 and glutathione protecting PC12 cells from oxidative stress via activation of Nrf2-ARE signaling pathway [107] which indirectly suggests a potential role in AD treatment. Similarly, using primary neuronal cultures, resveratrol was able to significantly induce $\mathrm{HO}-1$, presumably through the activation of Nrf2 [108]. Yet, curcumin induces HO-1 increasing tolerance of the brain to stresses and providing an important antidegenerative function in $\mathrm{AD}$ pathogenesis [109]. Moreover, curcumin activates GST [110] restoring GSH content in the brain and improving cognitive deficits [111]. Recently, consistent with the potential role of $\mathrm{Nrf} 2$ as therapeutic target in $\mathrm{AD}$, it was observed that the incubation of $\mathrm{Nrf}^{+/+}$astrocytes with curcumin led to a significant induction of phase II enzymes [112]. Additionally, data from our laboratory have shown the ability of low dose EGCG to stimulate HO-1 expression in rat cultured neurons. In this study, Nrf2 was found to be upregulated in neurons exposed to nontoxic concentrations of EGCG, suggesting that this compound may induce $\mathrm{HO}-1$ via the activation of Nrf2 [113]. These results are in agreement with another study, where it was showed the ability of epicatechins to protect neurons and reduce brain infarct size of mice. Moreover, neuroprotection was abolished in neurons derived from knockout mice for HO-1 and Nrf2 [114]. In conclusion, Nrf2 is an attractive target for the discovery of natural neuroprotective agents against $\mathrm{AD}$ and these few examples can already be considered promising.

\section{Cocktail of Drugs for Neuroprotection}

Given the complexity and the multiple etiological nature of $\mathrm{AD}$ and other neurodegenerative disorders, a successful treatment may require a cocktail of compounds. Indeed, therapeutic approaches that are based on single biological mechanisms or targets may be inadequate. Also considering that certain regions of the brain respond differently to the treatments or are more affected than others, a cocktail of drugs may be more effective. Despite this, almost no studies have been done with a combination of neuroprotective drugs, especially with curcumin or resveratrol. However, new drug candidates for $\mathrm{AD}$ should be able to act on multiple brain targets for the treatment of cognition impairment, motor dysfunction, depression, and neurodegeneration. It is evident that the neurodegenerative disorders require multiple-target therapies to counteract the heterogeneous pathological aspects of the disease. For instance, a multifunctional neuroprotective-neurorescue compound might be endowed with properties that include (1) antifibrils formation and fibrils destabilizing action; (2) promotion of neurite outgrowth; (3) a direct neutralization of free-radicals-induced oxidative stress; (4) maintenance of mitochondrial integrity; (5) modulation of the activity of antioxidant detoxifying enzymes; (6) reduction in $\mathrm{A} \beta \mathrm{PP} / \alpha$ synuclein translation; (7) activation of transcription factors; (8) attenuation of reactive free-iron pool. To date, it is plausible that some of these actions may result only from a combination therapy of more compounds. In human neuroblastoma cells, EGCG causes a rapid decrease in proapoptotic factors whereas R-apomorphine upregulates anti-apoptotic proteins [115] but both compounds are also iron chelators; therefore they complement each other and induce a synergistic neuroprotective action. However, it should be underlined that plant polyphenols are recognized as multifunctional agents for neuroprotection, providing polypharmacological activities in addition to their established radical scavenging action. Therefore, multidrug medication therapy can be effective because single-target approach may be inadequate for heterogeneous disorders but at the same time one compound with two or more mechanisms of action, targeted at different pathological aspects of the disease may offer a good therapeutic efficacy.

\section{Conclusions}

The pathogenesis of $\mathrm{AD}$ is multilateral and its polyetiological origin requires new drug candidates capable to operate on multiple brain targets for the treatment of cognition and motor dysfunction, depression, and neurodegeneration. In this paper we present some phytochemical entities able to act on specific targets implicated in the pathogenesis of $\mathrm{AD}$. The neuroprotective activity of curcumin, EGCG, and resveratrol has been demonstrated in vitro and in various models of neurodegenerative diseases in vivo. Consequently, it is reasonable to propose these substances as promising resources in the development of new medications for $\mathrm{AD}$ aimed to prevent and/or to treat this neurodegenerative disorder. Additionally, even though there are limits for their widespread use, such protective molecules appear to be innocuous, tolerate, inexpensive, and available. However, their efficacy and utility in the clinical pharmaceutical is still an open question because an exhaustive amount of experimental evidence is still missing. In addition, although the neuroprotective effects of the phytocompounds above described are attractive for their multiple biological activities, more long-term studies should be performed at least to determine their effects in slowing the development of AD. Furthermore, it is still unclear which is the ideal concentration for the compound to be in the active forms and exert its beneficial effects. In conclusion, polyphenols have revealed to be in the field of neurosciences promising neuroprotective compounds with great potential that continues to expand.

\section{Acknowledgments}

The present work was supported in partnership with Medestea International S.p.A. (Italy). The authors would like to express their appreciation and gratitude to the Medestea Group for their support in the research on bioactive plant polyphenols.

\section{References}

[1] D. A. Butterfield, S. Griffin, G. Munch, and G. M. Pasinetti, "Amyloid $\beta$-peptide and amyloid pathology are central to the oxidative stress and inflammatory cascades under 
which Alzheimer's disease brain exists," Journal of Alzheimer's Disease, vol. 4, no. 3, pp. 193-201, 2002.

[2] M. T. Heneka and M. K. O’Banion, "Inflammatory processes in Alzheimer's disease," Journal of Neuroimmunology, vol. 184, no. 1-2, pp. 69-91, 2007.

[3] K. A. Wollen, “Alzheimer's disease: the pros and cons of pharmaceutical, nutritional, botanical, and stimulatory therapies, with a discussion of treatment strategies from the perspective of patients and practitioners," Alternative Medicine Review, vol. 15, no. 3, pp. 223-244, 2010.

[4] R. Williams, "Biomarkers: warning signs," Nature, vol. 475, no. 7355, pp. S5-S7, 2011.

[5] M. Singh, M. Arseneault, T. Sanderson, V. Murthy, and C. Ramassamy, "Challenges for research on polyphenols from foods in Alzheimer's disease: bioavailability, metabolism, and cellular and molecular mechanisms," Journal of Agricultural and Food Chemistry, vol. 56, no. 13, pp. 4855-4873, 2008.

[6] P. L. Le Bars, M. M. Katz, N. Berman, T. M. Itil, A. M. Freedman, and A. F. Schatzberg, "A placebo-controlled, doubleblind, randomized trial of an extract of Ginkgo biloba for dementia," Journal of the American Medical Association, vol. 278, no. 16, pp. 1327-1332, 1997.

[7] H. P. Ammon and M. A. Wahl, "Pharmacology of Curcuma longa," Planta Medica, vol. 57, no. 1, pp. 1-7, 1991.

[8] F. Payton, P. Sandusky, and W. L. Alworth, "NMR study of the solution structure of curcumin," Journal of Natural Products, vol. 70, no. 2, pp. 143-146, 2007.

[9] K. C. Das and C. K. Das, "Curcumin (diferuloylmethane), a singlet oxygen ${ }^{1} \mathrm{O}_{2}$ quencher," Biochemical and Biophysical Research Communications, vol. 295, no. 1, pp. 62-66, 2002.

[10] R. S. Ramsewak, D. L. DeWitt, and M. G. Nair, "Cytotoxicity, antioxidant and anti-inflammatory activities of curcumins IIII from Curcuma longa," Phytomedicine, vol. 7, no. 4, pp. 303-308, 2000.

[11] K. Ono, K. Hasegawa, H. Naiki, and M. Yamada, "Curcumin has potent anti-amyloidogenic effects for Alzheimer's $\beta$ amyloid fibrils in vitro," Journal of Neuroscience Research, vol. 75, no. 6, pp. 742-750, 2004.

[12] G. Scapagnini, S. Vasto, N. G. Abraham, C. Caruso, D. Zella, and F. Galvano, "Modulation of nrf2/are pathway by food polyphenols: a nutritional neuroprotective strategy for cognitive and neurodegenerative disorders," Molecular Neurobiology, vol. 44, no. 2, p. 202, 2011.

[13] A. Sreejayan and M. N. Rao, "Nitric oxide scavenging by curcuminoids," Journal of Pharmacy and Pharmacology, vol. 49, no. 1, pp. 105-107, 1997.

[14] H. H. Tønnesen, M. Másson, and T. Loftsson, "Studies of curcumin and curcuminoids. XXVII. Cyclodextrin complexation: solubility, chemical and photochemical stability," International Journal of Pharmaceutics, vol. 244, no. 1-2, pp. 127-135, 2002.

[15] R. A. Sharma, A. J. Gescher, and W. P. Steward, "Curcumin: the story so far," European Journal of Cancer, vol. 41, no. 13, pp. 1955-1968, 2005.

[16] H. Itokawa, Q. Shi, T. Akiyama, S. L. Morris-Natschke, and K. H. Lee, "Recent advances in the investigation of curcuminoids," Chinese Medicine, vol. 3, article 11, 2008.

[17] R. Motterlini, R. Foresti, R. Bassi, and C. J. Green, "Curcumin, an antioxidant and anti-inflammatory agent, induces heme oxygenase-1 and protects endothelial cells against oxidative stress," Free Radical Biology and Medicine, vol. 28, no. 8, pp. 1303-1312, 2000.

[18] W. F. Chen, S. L. Deng, B. Zhou, L. Yang, and Z. L. Liu, "Curcumin and its analogues as potent inhibitors of low density lipoprotein oxidation: $\mathrm{H}$-atom abstraction from the phenolic groups and possible involvement of the 4-hydroxy3-methoxyphenyl groups," Free Radical Biology and Medicine, vol. 50, no. 3, p. 484, 2011.

[19] A. Barzegar and A. A. Moosavi-Movahedi, "Intracellular ROS protection efficiency and free radical-scavenging activity of curcumin," PLoS ONE, vol. 6, no. 10, Article ID e26012, 2011.

[20] G. P. Lim, T. Chu, F. Yang, W. Beech, S. A. Frautschy, and G. M. Cole, "The curry spice curcumin reduces oxidative damage and amyloid pathology in an Alzheimer transgenic mouse," Journal of Neuroscience, vol. 21, no. 21, pp. 83708377, 2001.

[21] B. K. Adams, J. Cai, J. Armstrong et al., "EF24, a novel synthetic curcumin analog, induces apoptosis in cancer cells via a redox-dependent mechanism," Anti-Cancer Drugs, vol. 16, no. 3, pp. 263-275, 2005.

[22] M. Gu, A. D. Owen, S. E. K. Toffa et al., "Mitochondrial function, GSH and iron in neurodegeneration and Lewy body diseases," Journal of the Neurological Sciences, vol. 158, no. 1, pp. 24-29, 1998.

[23] H. Liu, L. E. Harrell, S. Shenvi, T. Hagen, and R. M. Liu, "Gender differences in glutathione metabolism in Alzheimer's disease," Journal of Neuroscience Research, vol. 79, no. 6, pp. 861-867, 2005.

[24] D. A. Dickinson, K. E. Iles, H. Zhang, V. Blank, and H. J. Forman, "Curcumin alters EpRE and AP-1 binding complexes and elevates glutamate-cysteine ligase gene expression," FASEB Journal, vol. 17, no. 3, pp. 473-475, 2003.

[25] A. Rajeswari, "Curcumin protects mouse brain from oxidative stress caused by 1-methyl-4-phenyl-1,2,3,6-tetrahydro pyridine," European Review for Medical and Pharmacological Sciences, vol. 10, no. 4, pp. 157-161, 2006.

[26] Y. J. Zhang, Y. F. Xu, Y. H. Liu et al., "Peroxynitrite induces Alzheimer-like tau modifications and accumulation in rat brain and its underlying mechanisms," FASEB Journal, vol. 20, no. 9, pp. 1431-1442, 2006.

[27] M. O. Iwunze and D. McEwan, "Peroxynitrite interaction with curcumin solubilized in ethanolic solution," Cellular and Molecular Biology, vol. 50, no. 6, pp. 749-752, 2004.

[28] D. G. Smith, R. Cappai, and K. J. Barnham, "The redox chemistry of the Alzheimer's disease amyloid $\beta$ peptide," Biochimica et Biophysica Acta, vol. 1768, no. 8, pp. 1976-1990, 2007.

[29] W. D. Parker Jr., J. Parks, C. M. Filley, and B. K. KleinschmidtDeMasters, "Electron transport chain defects in Alzheimer's disease brain," Neurology, vol. 44, no. 6, pp. 1090-1096, 1994.

[30] E. M. Mutisya, A. C. Bowling, and M. F. Beal, "Cortical cytochrome oxidase activity is reduced in Alzheimer's disease," Journal of Neurochemistry, vol. 63, no. 6, pp. 2179-2184, 1994.

[31] H. Atamna and K. Boyle, "Amyloid- $\beta$ peptide binds with heme to form a peroxidase: relationship to the cytopathologies of Alzheimer's disease," Proceedings of the National Academy of Sciences of the United States of America, vol. 103, no. 9, pp. 3381-3386, 2006.

[32] J. S. Seo, Y. H. Leem, K. W. Lee, S. W. Kim, J. K. Lee, and P. L. Han, "Severe motor neuron degeneration in the spinal cord of the Tg2576 mouse model of Alzheimer disease," Journal of Alzheimer's Disease, vol. 21, no. 1, pp. 263-276, 2010.

[33] Y. G. Zhu, X. C. Chen, Z. Z. Chen et al., "Curcumin protects mitochondria from oxidative damage and attenuates apoptosis in cortical neurons," Acta Pharmacologica Sinica, vol. 25, no. 12, pp. 1606-1612, 2004. 
[34] H. Raza, A. John, E. M. Brown, S. Benedict, and A. Kambal, "Alterations in mitochondrial respiratory functions, redox metabolism and apoptosis by oxidant 4-hydroxynonenal and antioxidants curcumin and melatonin in PC12 cells," Toxicology and Applied Pharmacology, vol. 226, no. 2, pp. 161-168, 2008.

[35] L. Baum and A. Ng, "Curcumin interaction with copper and iron suggests one possible mechanism of action in Alzheimer's disease animal models," Journal of Alzheimer's Disease, vol. 6, no. 4, pp. 367-377, 2004.

[36] Y. Jiao IV, J. Wilkinson, E. Christine Pietsch et al., "Iron chelation in the biological activity of curcumin," Free Radical Biology and Medicine, vol. 40, no. 7, pp. 1152-1160, 2006.

[37] A. I. Bush, W. H. Pettingell, G. Multhaup et al., "Rapid induction of Alzheimer A $\beta$ amyloid formation by zinc," Science, vol. 265, no. 5177, pp. 1464-1467, 1994.

[38] M. Stoltenberg, A. I. Bush, G. Bach et al., "Amyloid plaques arise from zinc-enriched cortical layers in APP/PS1 transgenic mice and are paradoxically enlarged with dietary zinc deficiency," Neuroscience, vol. 150, no. 2, pp. 357-369, 2007.

[39] S. Davinelli, M. Intrieri, C. Russo et al., "The "Alzheimer's disease signature": potential perspectives for novel biomarkers," Immunity and Ageing, vol. 8, no. 7, 2011.

[40] C. Y. Jin, J. D. Lee, C. Park, Y. H. Choi, and G. Y. Kim, "Curcumin attenuates the release of pro-inflammatory cytokines in lipopolysaccharide-stimulated BV2 microglia," Acta Pharmacologica Sinica, vol. 28, no. 10, pp. 1645-1651, 2007.

[41] A. C. Bharti, N. Donato, and B. B. Aggarwal, "Curcumin (diferuloylmethane) inhibits constitutive and IL-6-inducible STAT3 phosphorylation in human multiple myeloma cells," Journal of Immunology, vol. 171, no. 7, pp. 3863-3871, 2003.

[42] A. Bierhaus, Y. Zhang, P. Quehenberger et al., "The dietary pigment curcumin reduces endothelial tissue factor gene expression by inhibiting binding of AP- 1 to the DNA and activation of NF- $\kappa \mathrm{B}$," Thrombosis and Haemostasis, vol. 77, no. 4, pp. 772-782, 1997.

[43] Y. X. Xu, K. R. Pindolia, N. Janakiraman, R. A. Chapman, and S. C. Gautam, "Curcumin inhibits IL $1 \alpha$ and TNF $\alpha$ induction of AP-1 and NF-kB DNA-binding activity in bone marrow stromal cells," Hematopathology and Molecular Hematology, vol. 11, no. 1, pp. 49-62, 1997-1998.

[44] G. Kang, P. J. Kong, Y. J. Yuh et al., "Curcumin suppresses lipopolysaccharide-induced cyclooxygenase- 2 expression by inhibiting activator protein 1 and nuclear factor $\kappa \mathrm{B}$ bindings in BV2 microglial cells," Journal of Pharmacological Sciences, vol. 94, no. 3, pp. 325-328, 2004.

[45] I. Brouet and H. Ohshima, "Curcumin, an anti-tumour promoter and anti-inflammatory agent, inhibits induction of nitric oxide synthase in activated macrophages," Biochemical and Biophysical Research Communications, vol. 206, no. 2, pp. 533-540, 1995.

[46] A. A. Nanji, K. Jokelainen, G. L. Tipoe, A. Rahemtulla, P. Thomas, and A. J. Dannenberg, "Curcumin prevents alcoholinduced liver disease in rats by inhibiting the expression of NF- $\kappa$ B-dependent genes," American Journal of Physiology, vol. 284, no. 2, pp. 321-327, 2003.

[47] I. Rahman, J. Marwick, and P. Kirkham, "Redox modulation of chromatin remodeling: impact on histone acetylation and deacetylation, NF- $\kappa \mathrm{B}$ and pro-inflammatory gene expression," Biochemical Pharmacology, vol. 68, no. 6, pp. 12551267, 2004.

[48] S. Bengmark, "Curcumin, an atoxic antioxidant and natural $\mathrm{NF} \kappa \mathrm{B}$, cyclooxygenase-2, lipooxygenase, and inducible nitric oxide synthase inhibitor: a shield against acute and chronic diseases," Journal of Parenteral and Enteral Nutrition, vol. 30, no. 1, pp. 45-51, 2006.

[49] S. L. Hae, K. K. Jung, J. Y. Cho et al., "Neuroprotective effect of curcumin is mainly mediated by blockade of microglial cell activation," Pharmazie, vol. 62, no. 12, pp. 937-942, 2007.

[50] G. M. Cole, B. Teter, and S. A. Frautschy, "Neuroprotective effects of curcumin," Advances in Experimental Medicine and Biology, vol. 595, pp. 197-212, 2007.

[51] M. Garcia-Alloza, L. A. Borrelli, A. Rozkalne, B. T. Hyman, and B. J. Bacskai, "Curcumin labels amyloid pathology in vivo, disrupts existing plaques, and partially restores distorted neurites in an Alzheimer mouse model," Journal of Neurochemistry, vol. 102, no. 4, pp. 1095-1104, 2007.

[52] S. A. Frautschy, W. Hu, P. Kim et al., "Phenolic antiinflammatory antioxidant reversal of $\mathrm{A} \beta$-induced cognitive deficits and neuropathology," Neurobiology of Aging, vol. 22, no. 6, pp. 993-1005, 2001.

[53] K. Ohtsuka and T. Suzuki, "Roles of molecular chaperones in the nervous system," Brain Research Bulletin, vol. 53, no. 2, pp. 141-146, 2000.

[54] D. Yanagisawa, N. Shirai, T. Amatsubo et al., "Relationship between the tautomeric structures of curcumin derivatives and their $\mathrm{A} \beta$-binding activities in the context of therapies for Alzheimer's disease," Biomaterials, vol. 31, no. 14, pp. 41794185, 2010.

[55] P. Dadhaniya, C. Patel, J. Muchhara et al., "Safety assessment of a solid lipid curcumin particle preparation: acute and subchronic toxicity studies," Food and Chemical Toxicology, vol. 49, no. 8, pp. 1834-1842, 2011.

[56] O. Weinreb, T. Amit, and M. B. H. Youdim, "The application of proteomics for studying the neurorescue activity of the polyphenol (-)-epigallocatechin-3-gallate," Archives of Biochemistry and Biophysics, vol. 476, no. 2, pp. 152-160, 2008.

[57] A. Faria, D. Pestana, D. Teixeira et al., "Insights into the putative catechin and epicatechin transport across bloodbrain barrier," Food and Function, vol. 2, no. 1, pp. 39-44, 2011.

[58] L. C. Lin, M. N. Wang, T. Y. Tseng, J. S. Sung, and T. H. Tsai, "Pharmacokinetics of (-)-epigallocatechin-3-gallate in conscious and freely moving rats and its brain regional distribution," Journal of Agricultural and Food Chemistry, vol. 55, no. 4, pp. 1517-1524, 2007.

[59] S. T. Yin, M. L. Tang, H. M. Deng et al., "Epigallocatechin-3gallate induced primary cultures of rat hippocampal neurons death linked to calcium overload and oxidative stress," Naunyn-Schmiedeberg's Archives of Pharmacology, vol. 379, no. 6, pp. 551-564, 2009.

[60] J. H. Wang, J. Cheng, C. R. Li, M. Ye, Z. Ma, and F. Cai, "Modulation of $\mathrm{Ca}^{2+}$ signals by epigallocatechin-3-gallate(EGCG) in cultured rat hippocampal neurons," International Journal of Molecular Sciences, vol. 12, no. 1, pp. 742-754, 2011.

[61] N. Dragicevic, A. Smith, X. Lin et al., "Green tea epigallocatechin-3-gallate (EGCG) and other flavonoids reduce Alzheimer's amyloid-induced mitochondrial dysfunction," Journal Alzheimer Disease, vol. 26, no. 3, pp. 507-521, 2011.

[62] S. Mandel and M. B. H. Youdim, "Catechin polyphenols: neurodegeneration and neuroprotection in neurodegenerative diseases," Free Radical Biology and Medicine, vol. 37, no. 3, pp. 304-317, 2004.

[63] S. J. Lee and K. W. Lee, "Protective effect of (-)-epigallocatechin gallate against advanced glycation endproductsinduced injury in neuronal cells," Biological and Pharmaceutical Bulletin, vol. 30, no. 8, pp. 1369-1373, 2007. 
[64] C. Y. Kim, C. Lee, G. H. Park, and J. H. Jang, "Neuroprotective effect of epigallocatechin-3-gallate against $\beta$-amyloidinduced oxidative and nitrosative cell death via augmentation of antioxidant defense capacity," Archives of Pharmacal Research, vol. 32, no. 6, pp. 869-881, 2009.

[65] M. He, L. Zhao, M. J. Wei, W. F. Yao, H. S. Zhao, and F. J. Chen, "Neuroprotective effects of (-)-epigallocatechin-3gallate on aging mice induced by D-galactose," Biological and Pharmaceutical Bulletin, vol. 32, no. 1, pp. 55-60, 2009.

[66] S. M. Lin, S. W. Wang, S. C. Ho, and Y. L. Tang, "Protective effect of green tea (-)-epigallocatechin-3-gallate against the monoamine oxidase B enzyme activity increase in adult rat brains," Nutrition, vol. 26, no. 11-12, pp. 1195-1200, 2010.

[67] K. Nagai, M. H. Jiang, J. Hada et al., “(-)-Epigallocatechin gallate protects against NO stress-induced neuronal damage after ischemia by acting as an anti-oxidant," Brain Research, vol. 956, no. 2, pp. 319-322, 2002.

[68] N. R. Perron, J. N. Hodges, M. Jenkins, and J. L. Brumaghim, "Predicting how polyphenol antioxidants prevent DNA damage by binding to iron," Inorganic Chemistry, vol. 47, no. 14, pp. 6153-6161, 2008.

[69] Y. Levites, T. Amit, S. Mandel, and M. B. H. Youdim, "Neuroprotection and neurorescue against Abeta toxicity and PKCdependent release of nonamyloidogenic soluble precursor protein by green tea polyphenol (-)-epigallocatechin-3gallate," FASEB Journal, vol. 17, no. 8, pp. 952-954, 2003.

[70] Y. Levites, T. Amit, M. B. H. Youdim, and S. Mandel, "Involvement of protein kinase $\mathrm{C}$ activation and cell sur$\mathrm{vival} /$ cell cycle genes in green tea polyphenol (-)-epigallocatechin 3-gallate neuroprotective action," Journal of Biological Chemistry, vol. 277, no. 34, pp. 30574-30580, 2002.

[71] S. J. Kim, H. J. Jeong, K. M. Lee et al., "Epigallocatechin-3gallate suppresses NF- $\kappa \mathrm{B}$ activation and phosphorylation of p38 MAPK and JNK in human astrocytoma U373MG cells," Journal of Nutritional Biochemistry, vol. 18, no. 9, pp. 587596, 2007.

[72] J. P. E. Spencer, "Flavonoids: modulators of brain function?" British Journal of Nutrition, vol. 99, no. 1, pp. ES60-ES77, 2008.

[73] Y. K. Lee, D. Y. Yuk, J. W. Lee et al., “(-)-Epigallocatechin3 -gallate prevents lipopolysaccharide-induced elevation of beta-amyloid generation and memory deficiency," Brain Research, vol. 1250, pp. 164-174, 2009.

[74] K. Rezai-Zadeh, D. Shytle, N. Sun et al., "Green tea epigallocatechin-3-gallate (EGCG) modulates amyloid precursor protein cleavage and reduces cerebral amyloidosis in Alzheimer transgenic mice," Journal of Neuroscience, vol. 25, no. 38, pp. 8807-8814, 2005.

[75] K. Rezai-Zadeh, G. W. Arendash, H. Hou et al., "Green tea epigallocatechin-3-gallate (EGCG) reduces $\beta$-amyloid mediated cognitive impairment and modulates tau pathology in Alzheimer transgenic mice," Brain Research, vol. 1214, pp. 177-187, 2008.

[76] D. E. Ehrnhoefer, J. Bieschke, A. Boeddrich et al., "EGCG redirects amyloidogenic polypeptides into unstructured, offpathway oligomers," Nature Structural and Molecular Biology, vol. 15, no. 6, pp. 558-566, 2008.

[77] K. Ono, Y. Yoshiike, A. Takashima, K. Hasegawa, H. Naiki, and M. Yamada, "Potent anti-amyloidogenic and fibrildestabilizing effects of polyphenols in vitro: implications for the prevention and therapeutics of Alzheimer's disease," Journal of Neurochemistry, vol. 87, no. 1, pp. 172-181, 2003.

[78] S. Y. Jeon, K. Bae, Y. H. Seong, and K. S. Song, "Green tea catechins as BACE1 ( $\beta$-secretase) inhibitor," Bioorganic and
Medicinal Chemistry Letters, vol. 13, no. 22, pp. 3905-3908, 2003.

[79] D. F. Obregon, K. Rezai-Zadeh, Y. Bai et al., "ADAM10 activation is required for green tea (-)-epigallocatechin-3gallate- induced $\alpha$-secretase cleavage of amyloid precursor protein," Journal of Biological Chemistry, vol. 281, no. 24, pp. 16419-16427, 2006.

[80] J. W. Lee, Y. K. Lee, J. O. Ban et al., "Green tea (-)-epigallocatechin-3-gallate inhibits $\beta$-amyloid-induced cognitive dysfunction through modification of secretase activity via inhibition of ERK and NF- $\kappa$ B pathways in mice," Journal of Nutrition, vol. 139, no. 10, pp. 1987-1993, 2009.

[81] B. Giunta, H. Hou, Y. Zhu et al., "Fish oil enhances antiamyloidogenic properties of green tea EGCG in Tg2576 mice," Neuroscience Letters, vol. 471, no. 3, pp. 134-138, 2010.

[82] Q. Li, H. F. Zhao, Z. F. Zhang et al., "Long-term green tea catechin administration prevents spatial learning and memory impairment in senescence-accelerated mouse prone8 mice by decreasing A $\beta 1-42$ oligomers and upregulating synaptic plasticity-related proteins in the hippocampus," Neuroscience, vol. 163, no. 3, pp. 741-749, 2009.

[83] J. A. Baur, K. J. Pearson, N. L. Price et al., "Resveratrol improves health and survival of mice on a high-calorie diet," Nature, vol. 444, no. 7117, pp. 337-342, 2006.

[84] J. A. Baur and D. A. Sinclair, "Therapeutic potential of resveratrol: the in vivo evidence," Nature Reviews Drug Discovery, vol. 5, no. 6, pp. 493-506, 2006.

[85] F. Caruso, J. Tanski, A. Villegas-Estrada, and M. Rossi, "Structural basis for antioxidant activity of trans-resveratrol: Ab initio calculations and crystal and molecular structure," Journal of Agricultural and Food Chemistry, vol. 52, no. 24, pp. 7279-7285, 2004.

[86] M. Mokni, S. Elkahoui, F. Limam, M. Amri, and E. Aouani, "Effect of resveratrol on antioxidant enzyme activities in the brain of healthy rat," Neurochemical Research, vol. 32, no. 6, pp. 981-987, 2007.

[87] A. Kumar, P. S. Naidu, N. Seghal, and S. S. V. Padi, "Neuroprotective effects of resveratrol against intracerebroventricular colchicine-induced cognitive impairment and oxidative stress in rats," Pharmacology, vol. 79, no. 1, pp. 17-26, 2007.

[88] C. A. de la Lastra and I. Villegas, "Resveratrol as an antioxidant and pro-oxidant agent: mechanisms and clinical implications," Biochemical Society Transactions, vol. 35, no. 5, pp. 1156-1160, 2007.

[89] F. J. Alcaín and J. M. Villalba, "Sirtuin activators," Expert Opinion on Therapeutic Patents, vol. 19, no. 4, pp. 403-414, 2009.

[90] P. Saiko, A. Szakmary, W. Jaeger, and T. Szekeres, "Resveratrol and its analogs: defense against cancer, coronary disease and neurodegenerative maladies or just a fad?" Mutation Research, vol. 658, no. 1-2, pp. 68-94, 2008.

[91] J. Wang, L. Ho, W. Qin et al., "Caloric restriction attenuates $\beta$-amyloid neuropathology in a mouse model of Alzheimer's disease," FASEB Journal, vol. 19, no. 6, pp. 659-661, 2005.

[92] N. V. Patel, M. N. Gordon, K. E. Connor et al., "Caloric restriction attenuates $\mathrm{A} \beta$-deposition in Alzheimer transgenic models," Neurobiology of Aging, vol. 26, no. 7, pp. 995-1000, 2005.

[93] D. Kim, M. D. Nguyen, M. M. Dobbin et al., "SIRT1 deacetylase protects against neurodegeneration in models for Alzheimer's disease and amyotrophic lateral sclerosis," EMBO Journal, vol. 26, no. 13, pp. 3169-3179, 2007. 
[94] N. A. Kelsey, H. M. Wilkins, and D. A. Linseman, "Nutraceutical antioxidants as novel neuroprotective agents," Molecules, vol. 15, no. 11, pp. 7792-7814, 2010.

[95] C. Rivière, T. Richard, L. Quentin, S. Krisa, J. M. Mérillon, and J. P. Monti, "Inhibitory activity of stilbenes on Alzheimer's $\beta$-amyloid fibrils in vitro," Bioorganic and Medicinal Chemistry, vol. 15, no. 2, pp. 1160-1167, 2007.

[96] P. Marambaud, H. Zhao, and P. Davies, "Resveratrol promotes clearance of Alzheimer's disease amyloid- $\beta$ peptides," Journal of Biological Chemistry, vol. 280, no. 45, pp. 3737737382, 2005.

[97] B. L. Tang and C. E. L. Chua, "SIRT1 and neuronal diseases," Molecular Aspects of Medicine, vol. 29, no. 3, pp. 187-200, 2008.

[98] Y. Feng, X. P. Wang, S. G. Yang et al., "Resveratrol inhibits beta-amyloid oligomeric cytotoxicity but does not prevent oligomer formation," NeuroToxicology, vol. 30, no. 6, pp. 986-995, 2009.

[99] Y. S. Han, W. H. Zheng, S. Bastianetto, J. G. Chabot, and R. Quirion, "Neuroprotective effects of resveratrol against $\beta$ amyloid-induced neurotoxicity in rat hippocampal neurons: involvement of protein kinase C," British Journal of Pharmacology, vol. 141, no. 6, pp. 997-1005, 2004.

[100] E. Candelario-Jalil, A. C. P. de Oliveira, S. Gräf et al., "Resveratrol potently reduces prostaglandin $\mathrm{E}_{2}$ production and free radical formation in lipopolysaccharide-activated primary rat microglia," Journal of Neuroinflammation, vol. 4, article 25, 2007.

[101] Y. A. Kim, S. Y. Lim, S. H. Rhee et al., "Resveratrol inhibits inducible nitric oxide synthase and cyclooxygenase-2 expression in $\beta$-amyloid-treated C6 glioma cells," International Journal of Molecular Medicine, vol. 17, no. 6, pp. 1069-1075, 2006.

[102] X. Lu, L. Ma, L. Ruan et al., "Resveratrol differentially modulates inflammatory responses of microglia and astrocytes," Journal of Neuroinflammation, vol. 7, article 46, 2010.

[103] H. Inoue, X. F. Jiang, T. Katayama, S. Osada, K. Umesono, and S. Namura, "Brain protection by resveratrol and fenofibrate against stroke requires peroxisome proliferatoractivated receptor $\alpha$ in mice," Neuroscience Letters, vol. 352, no. 3, pp. 203-206, 2003.

[104] Y. J. Wang, F. He, and X. L. Li, "The neuroprotection of resveratrol in the experimental cerebral ischemia," Zhonghua Yi Xue Za Zhi, vol. 83, no. 7, pp. 534-536, 2003.

[105] S. S. Karuppagounder, J. T. Pinto, H. Xu, H. L. Chen, M. F. Beal, and G. E. Gibson, "Dietary supplementation with resveratrol reduces plaque pathology in a transgenic model of Alzheimer's disease," Neurochemistry International, vol. 54, no. 2, pp. 111-118, 2009.

[106] M. Manczak, P. Mao, M. J. Calkins et al., "Mitochondriatargeted antioxidants protect against amyloid- $\beta$ toxicity in Alzheimer's disease neurons," Journal of Alzheimer's Disease, vol. 20, supplement 2, pp. S609-S631, 2010.

[107] C. Y. Chen, J. H. Jang, M. H. Li, and Y. J. Surh, "Resveratrol upregulates heme oxygenase-1 expression via activation of NF-E2-related factor 2 in PC12 cells," Biochemical and Biophysical Research Communications, vol. 331, no. 4, pp. 993-1000, 2005.

[108] H. Zhuang, Y. S. Kim, R. C. Koehler, and S. Doré, "Potential mechanism by which resveratrol, a red wine constituent, protects neurons," Annals of the New York Academy of Sciences, vol. 993, pp. 276-288, 2003.
[109] G. Scapagnini, C. Colombrita, M. Amadio et al., "Curcumin activates defensive genes and protects neurons against oxidative stress," Antioxidants and Redox Signaling, vol. 8, no. 3-4, pp. 395-403, 2006.

[110] T. Nishinaka, Y. Ichijo, M. Ito et al., "Curcumin activates human glutathione $S$-transferase P1 expression through antioxidant response element," Toxicology Letters, vol. 170, no. 3, pp. 238-247, 2007.

[111] T. Ishrat, M. N. Hoda, M. B. Khan et al., "Amelioration of cognitive deficits and neurodegeneration by curcumin in rat model of sporadic dementia of Alzheimer's type (SDAT)," European Neuropsychopharmacology, vol. 19, no. 9, pp. 636$647,2009$.

[112] H. Jiang, X. Tian, Y. Guo, W. Duan, H. Bu, and C. Li, "Activation of nuclear factor erythroid 2-related factor 2 cytoprotective signaling by curcumin protect primary spinal cord astrocytes against oxidative toxicity," Biological Pharmaceutical Bulletin, vol. 34, no. 8, pp. 1194-1197, 2011.

[113] L. Romeo, M. Intrieri, V. D’Agata et al., “The major green tea polyphenol, (-)-epigallocatechin-3-gallate, induces heme oxygenase in rat neurons and acts as an effective neuroprotective agent against oxidative stress," Journal of the American College of Nutrition, vol. 28, supplement, pp. 492S-499S, 2009.

[114] Z. A. Shah, R. C. Li, A. S. Ahmad et al., "The flavanol (-)epicatechin prevents stroke damage through the $\mathrm{Nrf} 2 / \mathrm{HO} 1$ pathway," Journal of Cerebral Blood Flow and Metabolism, vol. 30, no. 12, pp. 1951-1961, 2010.

[115] O. Weinreb, S. Mandel, and M. B. H. Youdim, "cDNA gene expression profile homology of antioxidants and their antiapoptotic and proapoptotic activities in human neuroblastoma cells," FASEB Journal, vol. 17, no. 8, pp. 935-937, 2003. 


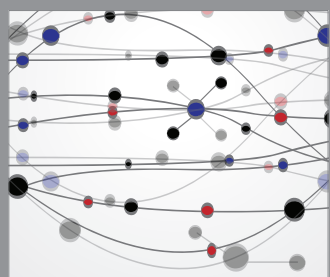

The Scientific World Journal
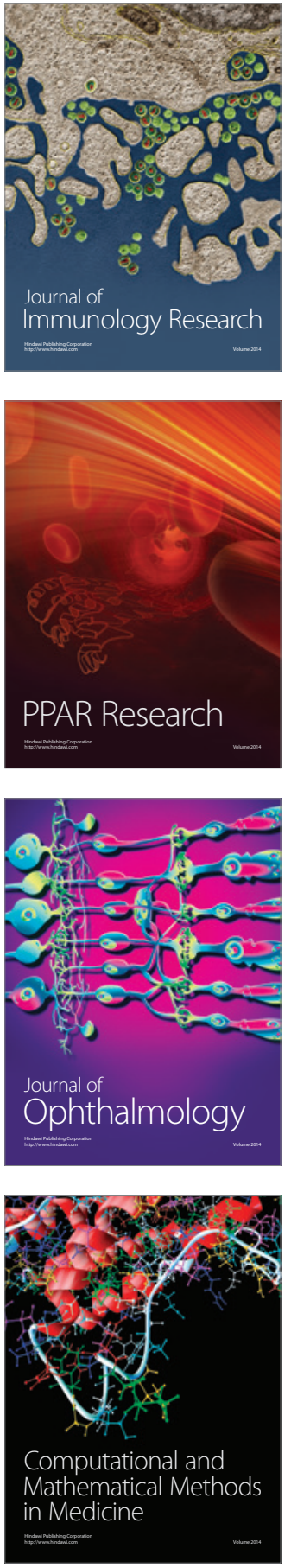

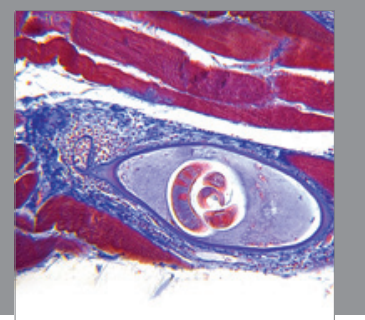

Gastroenterology

Research and Practice
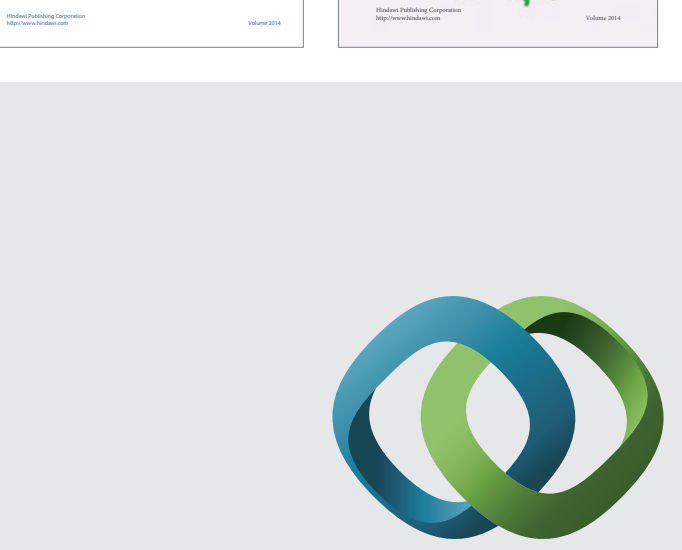

\section{Hindawi}

Submit your manuscripts at

http://www.hindawi.com
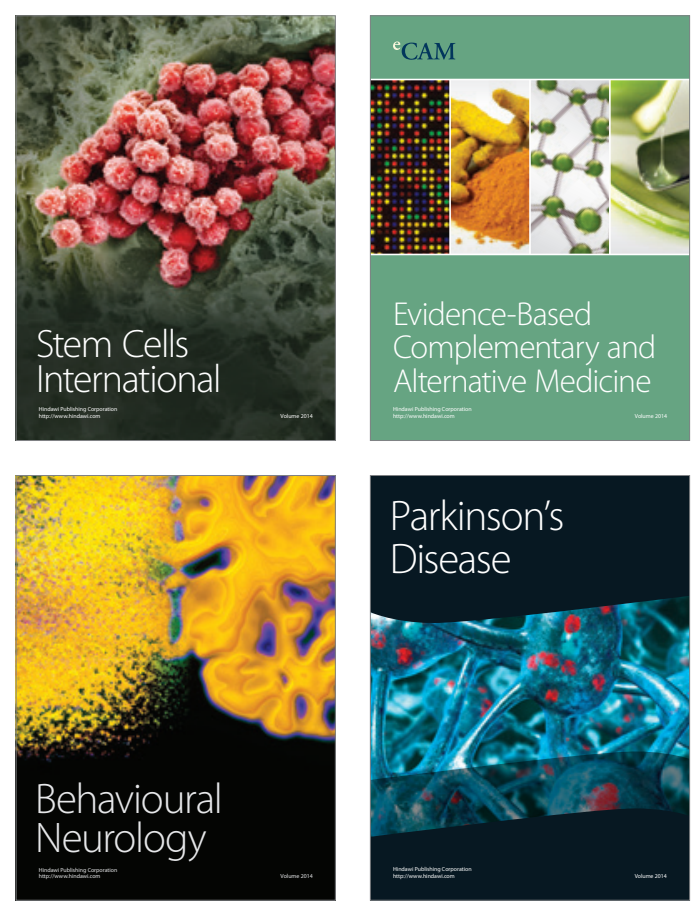

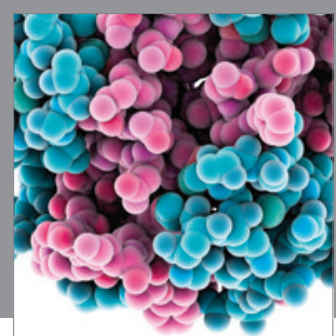

Journal of
Diabetes Research

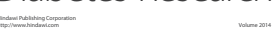

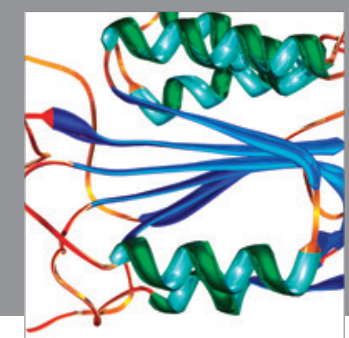

Disease Markers
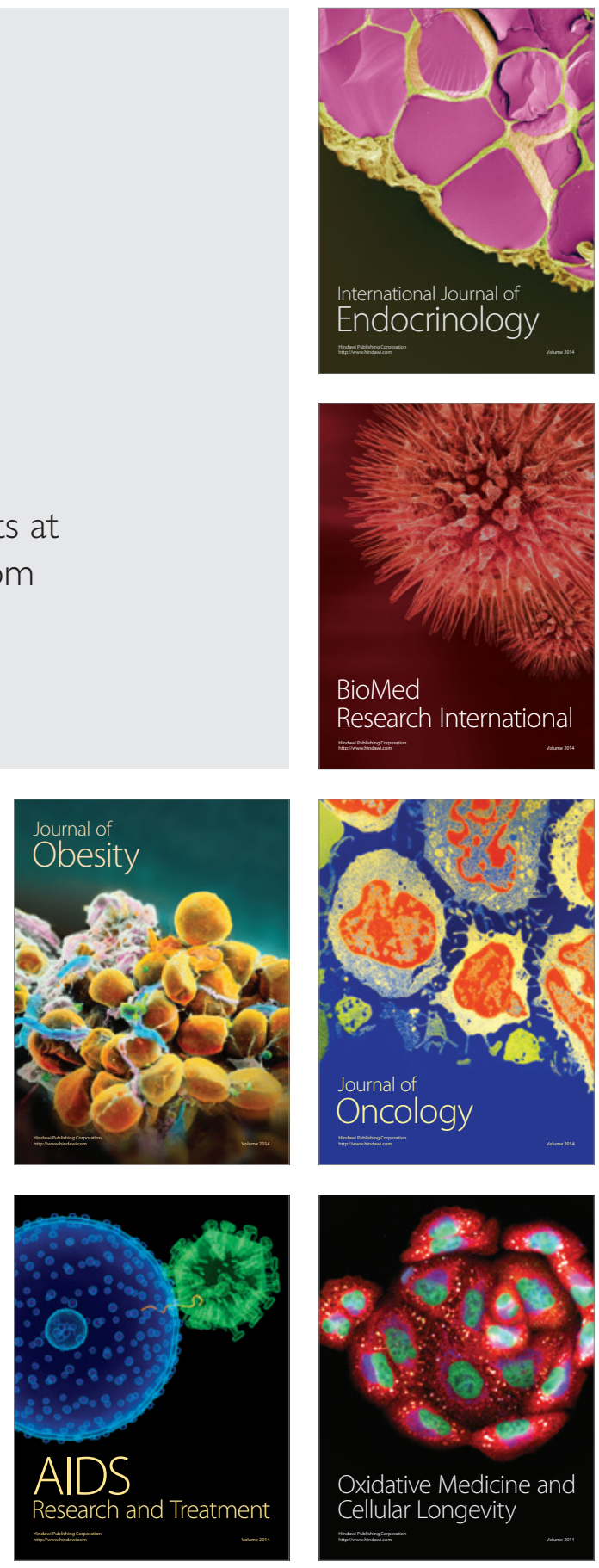